\title{
O Museu da Língua Portuguesa, na Estação da Luz
}

Consuelo Ivo

Editora executiva da revista Comunicação \& Educação.

Jornalista especialista em Gestão da Comunicação.

E-mail: consuelo.ivo@terra.com.br

Inaugurado em março de 2006, o Museu da Língua Portuguesa, na Estação da Luz, é a primeira instituição totalmente dedicada ao idioma original de um país. Com tecnologia de ponta, o museu apresenta toda a história da língua portuguesa, os vários idiomas que ajudaram a formá-la e a criação da língua na literatura brasileira. São três pisos unidos por dois elevadores panorâmicos, um painel de 106 metros com 11 projeções de vídeo simultâneas, em totens informatizados, e até em um jogo hi-tech, no qual o público manipula virtualmente sufixos e prefixos. Além das áreas para exposições temporárias, terminais multimídias e escritórios de gestão de conteúdo, o visitante também tem acesso

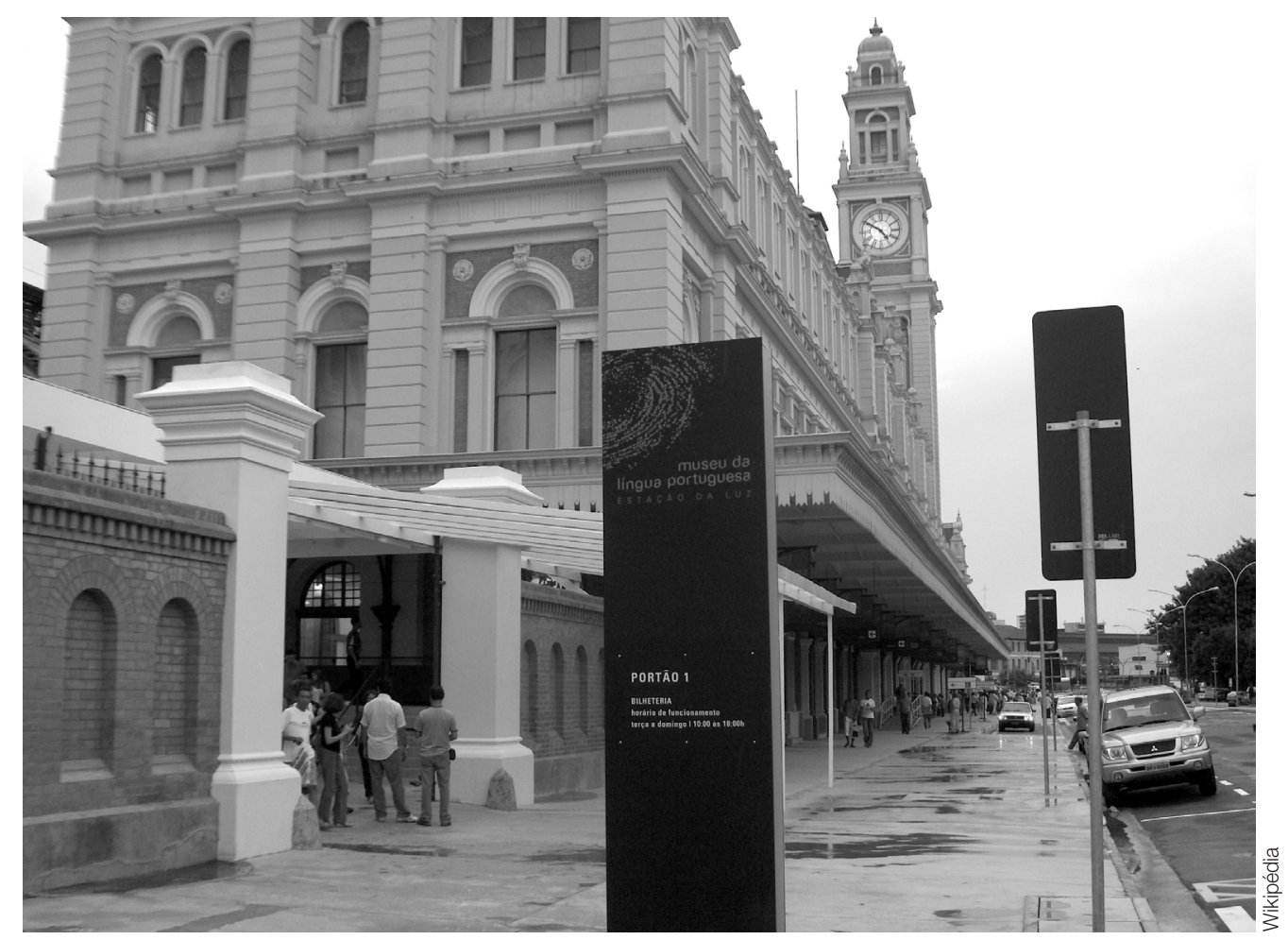

Museu da Língua Portuguesa. O tema central é a língua portuguesa, base da cultura brasileira. 
comunicação \& educação • Ano XI • Número 3 • set/dez 2006

à Grande Galeria, à Galeria das Influências, à Linha do Tempo e ao Beco das Palavras. Atualmente, o português é a língua oficial de oito países, de quatro continentes: Portugal, Angola, Moçambique, São Tomé e Príncipe, Guiné-Bissau, Cabo Verde e Timor Leste, além do Brasil.

\section{O PROJETO}

O Museu da Língua Portuguesa é ponto de encontro do visitante com a língua, a literatura e a história, exibidas por meio de recursos audiovisuais e tecnologia de ponta. No lugar de paredes, vozes. No lugar de obras, espaços interativos. No coração de São Paulo, na Estação da Luz, o museu proporciona uma viagem sensorial e subjetiva pela língua portuguesa, guiada por palavras, autores e estrelas do Brasil. O tema central do museu é a língua portuguesa, base da cultura brasileira. Trata-se de um museu vivo da língua, onde os brasileiros podem se reconhecer e se conhecer melhor, em um lugar que evoca a especificidade e a riqueza da língua portuguesa do Brasil e busca, assim, reforçar o sentimento de pertença e de responsabilidade para com o País, justificam os curadores.

O objetivo maior, segundo eles, é fazer com que as pessoas se surpreendam e descubram aspectos da língua que falam, lêem e escrevem, bem como da cultura do País em que vivem, nos quais nunca haviam pensado antes. Que se espantem ao descobrir que sua língua tem aspectos ocultos. $\mathrm{O}$ alvo, anunciam, é a média da população brasileira, mulheres e homens provenientes de todas as regiões e faixas sociais do Brasil e cujo nível de instrução é, na maioria, médio ou baixo. Essas pessoas, observam, utilizam o português - sua língua materna - das mais diversas maneiras: comunicam-se com muita criatividade, usam neologismos, inventam imagens, têm humor. Operam a língua com muita soltura, mas não têm idéia de sua história, de como ela se construiu e continua a construir-se, pondera o texto de justificativa do projeto. Deseja-se que, no museu, esse público tenha acesso a novos conhecimentos e reflexões, de maneira intensa e prazerosa.

\section{O MUSEU NO CORAÇÃO DA ESTAÇÃO DA LUZ}

Localizado no bairro da Luz, o prédio centenário da Estação da Luz constitui um dos mais importantes marcos históricos da cidade de São Paulo. Possui traçado arquitetônico peculiar. Foi construído pelos ingleses e inaugurado em 1901, no ciclo do café, com o intuito de levar a produção das lavouras do interior do estado até o Porto de Santos - canal de saída para a Europa, principal consumidora da bebida brasileira.

Hoje, mais de cem anos depois de sua inauguração, a Estação da Luz ainda é considerada símbolo da riqueza do café e um dos mais importantes monumentos arquitetônicos de São Paulo. 


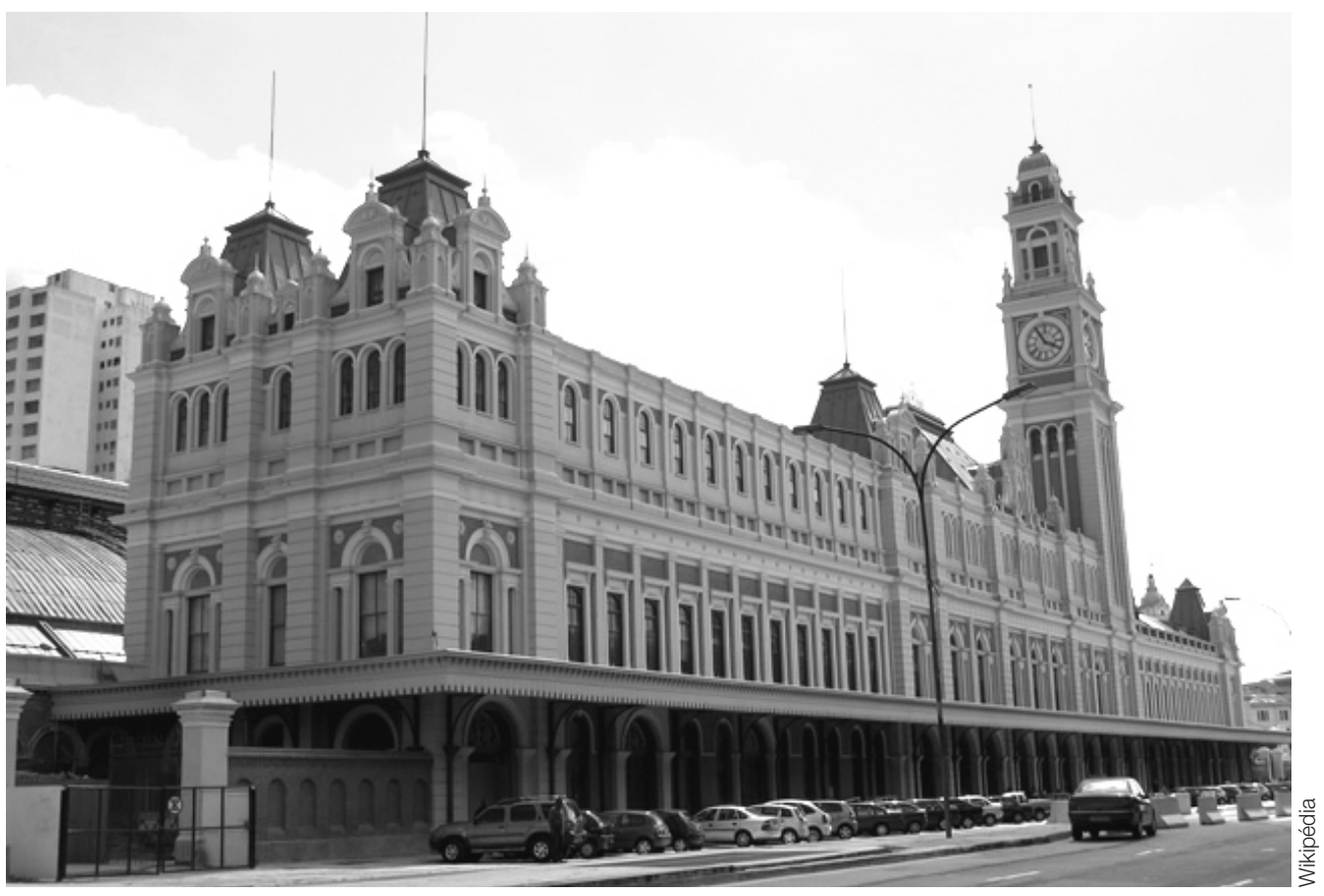

A Estação da Luz é um exemplo de diversidade e superação de barreiras lingüísticas, como ponto de encontro de sotaques de todas as regiões do País, que chegam a São Paulo em trens.

O local escolhido para a implantação do museu foi ponto de encontro entre o português falado aqui e os outros idiomas. Era na Luz que chegavam imigrantes vindos de trem do Porto de Santos. Hoje, a Estação recebe sotaques de todas as regiões do País. No prédio acima da plataforma da Luz funcionaram, no século XX, os escritórios da companhia férrea. Parte da construção foi destruída por um incêndio, em 1946, e reconstruída na década de 1950. Para a instalação do museu realizou-se um minucioso trabalho de revitalização e restauro. O projeto arquitetônico é de Paulo e Pedro Mendes da Rocha, pai e filho, que pela primeira vez trabalharam juntos. A museografia ficou sob responsabilidade do americano Ralph Appelbaum, o qual tem em seu currículo o Museu do Holocausto, em Washington. A elaboração de conteúdo foi coordenada pela socióloga Isa Grinspun Ferraz, que contou com uma equipe de cerca de 30 dos maiores especialistas em língua portuguesa do país.

Além dos recursos multimídia, o Museu da Língua Portuguesa terá oficinas de capacitação de professores, uma biblioteca - inicialmente, apenas para os professores - e computadores ligados a um portal na internet, para que todos possam consultá-lo.

Em suas novas funções como centro de valorização da língua, o Museu da Língua Portuguesa deve se transformar numa referência que coloque o entendimento da língua - e não apenas da língua falada no Brasil - em um novo patamar. Espera-se que as pessoas venham a São Paulo para experimentar a novidade. Mas o que pode levar as pessoas a passarem por essa experiência - ou seja, a tomarem consciência de sua cultura através do conhecimento da própria língua -, questionam os curadores? 
O museu organizou um vasto conjunto de informações a partir de alguns eixos centrais. O primeiro deles é a antigüidade da língua portuguesa, uma língua de milênios. Isso implica retraçar brevemente a sua trajetória, desde o Lácio, em Roma, até a chegada ao Brasil, depois de passar por outras partes do mundo. O segundo eixo é a universalidade da língua portuguesa. A idéia de globalização surgiu após Portugal ter alcançado a África, Índia e Ásia, com as grandes navegações. A viagem de circunavegação revelou a esfericidade da Terra. E a língua portuguesa foi introduzida em vários pontos do planeta. Os curadores lembram que universalidade, nesse caso, não significa que o português seja a língua mais falada no mundo. O terceiro aspecto destacado é quanto à mestiçagem da língua. O idioma falado no Brasil é tão misturado quanto a cor da pele das pessoas e a cultura do País. Assim, ele também está marcado pelos encontros e desencontros de povos e signos, por convergências e conflitos, por contradições e desigualdades. No Brasil, a língua, como as raças, amalgamou-se, dando unidade ao País. Além disso, foi a língua que, de certa forma, desenhou os limites do território brasileiro, com suas dimensões continentais: fez que um brasileiro da região Sul entendesse perfeitamente um brasileiro da Amazônia, apesar de ambos viverem em realidades culturais totalmente diferentes.

Um quarto aspecto abordado no museu diz respeito ao fato de que a língua portuguesa do Brasil está incessantemente construindo mundos, através das artes. É a matéria-prima por excelência da literatura e da poesia, e compõe também as artes visuais, o teatro, a música e as artes plásticas.

$\mathrm{O}$ que quer e o que pode essa língua, pergunta o poeta? $\mathrm{E}$ aqui se abre um universo extenso de referências: é Guimarães Rosa e Machado de Assis; é o cordel e João Cabral de Melo Neto; é Drummond e Bandeira; Mario e Oswald de Andrade; são os irmãos Haroldo e Augusto de Campos e Caetano Veloso; padre Vieira e Gregório de Matos; Chico Buarque e Glauber Rocha; Luiz Gonzaga e os samba-enredos; Wally Salomão, Marcelo D2 e Patativa do Assaré. A lista parece não ter fim.

Ao mesmo tempo, a língua estrutura nosso cotidiano em todo o País. Do jornal diário aos grafites das ruas, das juras de amor aos manuais, dos outdoors às placas de ônibus, das bulas de remédio às novelas e propagandas de TV, estamos imersos em um imenso manancial de informações veiculadas por meio da língua que falamos, lemos e escrevemos, lembram os responsáveis pelo projeto. Convivem no Brasil atual inúmeras variantes da língua, decorrentes das experiências regionais e locais, de especificidades socioculturais e dos cruzamentos que se vêm fazendo ao longo do tempo, com contribuições múltiplas.

\section{SIGNIFICADO DO PROJETO}

Os curadores do projeto questionam: qual seria a importância de tudo isso? Qual é a mensagem maior que se quer transmitir no Museu da Língua Portuguesa? O que se espera que as pessoas sintam depois de visitá-lo? 
A mensagem central contida no museu, asseguram eles, é a de que essa língua portuguesa que unifica um país do tamanho do Brasil representa a forma de expressão de uma cultura rica e diversa, a qual carrega consigo uma mensagem singular em meio às nações. Pois, apesar das grandes desigualdades sociais e econômicas em que está imerso, o Brasil tem como um de seus mais relevantes traços distintivos a capacidade de tolerância. Neste território, desenvolveram-se formas de convivência e respeito às diversidades de que o mundo necessita. Os brasileiros, porém - advertem -, não têm uma consciência muito profunda da civilização que construíram e dos valores que conquistaram através dessa civilização. Crêem-se inferiores a outros povos e culturas, o que os predispõe muitas vezes a receber e absorver toda e qualquer interferência que venha de fora, sem distinção. Trata-se, portanto, e antes de tudo, de ampliar a auto-estima dos brasileiros e fazê-los acreditar que, conhecendo-se a si mesmos, poderão inventar, com originalidade, o futuro que desejarem; e, ainda, mais do que uma celebração da língua, o Museu da Língua Portuguesa é, portanto, uma celebração da identidade brasileira - informam os curadores.

\section{OBJETIVOS DO MUSEU}

O projeto tem quatro objetivos básicos:

$1^{\circ}$ ) Oferecer ao público em geral um conjunto de informações audiovisuais de caráter histórico, social e cultural sobre a língua portuguesa em suas várias dimensões e possibilidades, organizado de maneira dinâmica e atraente em uma grande exposição permanente e em exposições temporárias.

$\left.2^{\circ}\right)$ Proporcionar a estudantes e estudiosos conferências, mesas-redondas, cursos e eventos interdisciplinares relativos à língua em seus vários aspectos.

$3^{\text {o) }}$ Gerar produtos educacionais, como monitoria para escolas e atividades para formação de professores.

$4^{\circ}$ ) Disponibilizar conteúdos virtuais através do Portal da Língua Portuguesa.

Os curadores lembram que já existe uma base sólida de conhecimentos produzidos sobre a língua e a cultura brasileira e que o Museu tem conexões com as instituições, os trabalhos e as pessoas que estão envolvidas nessa produção. Uma das características da língua portuguesa do Brasil, apontada pelos curadores como exemplo, é a forte presença em nosso vocabulário cotidiano de palavras indígenas e africanas, sendo desejável, portanto, que o museu se conecte a um grande número de instituições e especialistas que se dediquem ao estudo dessas línguas, disponibilizando para o público o acesso a esses acervos tecnológicos.

Há, além disso, um ingrediente geopolítico no Museu: um forte movimento dos países de língua espanhola, especialmente da Espanha, de afirmação da língua hispânica, com foco claro nos Estados Unidos e na Europa. O Museu pretende conectar-se também com esses ambientes no exterior para o fortalecimento do olhar sobre a língua portuguesa, transformando-se, para os brasileiros e para 
comunicação \& educação • Ano XI • Número 3 • set/dez 2006

os demais povos de língua, em um centro de referência da mesma natureza que um Instituto Goethe ou um Instituto Cervantes.

Nesse sentido, existem protocolos de intenção assinados com instituições internacionais, tais como a própria Comunidade dos Países de Língua Portuguesa - CPLP e o Instituto Camões, criado para a promoção da língua e cultura portuguesas, e uma importante parceria já firmada com a Fundação Calouste Gulbenkian, instituição de incentivo à arte, beneficência, ciência e educação, com sede em Lisboa. Talvez essa seja a primeira vez no mundo em que se pretendeu dar um tratamento museológico à língua, tomando-a como obra de arte. "Desejamos oferecer ao público a possibilidade de fruir sua língua, fazendo-o pensar nela como em uma invenção do homem”, declaram os curadores.

\section{A NATUREZA DA EXPERIÊNCIA}

O Museu da Língua Portuguesa, portanto:

- dirige-se a um público amplo e variado, de jovens e adultos, em um espaço atraente e instigante, estimulando atitudes pró-ativas, através de múltiplas possibilidades de interatividade;

- explora as potencialidades da língua portuguesa em seus aspectos temáticos e históricos;

- utiliza modernos recursos tecnológicos e de comunicação, tendo como matéria-prima básica iconografia variada, filmes, vídeos, música e poesia;

- oferece ao visitante momentos alternados de experiências individuais e coletivas, em um diálogo permanente e surpreendente entre conteúdos e abordagens variados;

- propicia uma experiência acolhedora e amplamente democrática.

\section{UM PORTAL INTERATIVO}

Assim como o museu, o Portal do Museu da Língua Portuguesa (http:// www.estacaodaluz.org.br) explora o tema com tecnologia e interatividade. Para dar cumprimento a esses objetivos, o Portal compreende os seguintes vínculos e respectivos links com seus conteúdos: Lingua Portuguesa - conjunto de textos sobre a língua e seu ensino. Língua falada - conjunto de transcrições de amostras da modalidade oral do português. Lingua escrita - conjunto de documentos sobre o português corrente e o português literário. Glossário e bibliografia - conjunto de definições de termos técnicos e informações bibliográficas. E ainda, o link Sobre o projeto, que traz a história do Museu da Língua Portuguesa.

\section{PARCEIROS}

O Museu da Língua Portuguesa, orçado em $\mathrm{R} \$ 37$ milhões, é resultado de uma parceria de empresas públicas e privadas sob a coordenação do governo 
do Estado de São Paulo, Secretaria de Educação e Secretaria de Cultura, e Fundação Roberto Marinho. O Ministério da Cultura foi responsável por $80 \%$ dos recursos investidos na construção do museu, por meio da Lei Federal de Incentivo à Cultura.

\section{PASSEIOS E SURPRESAS}

A Estação da Luz, que recebeu os primeiros imigrantes em São Paulo, abre suas portas para o visitante viajar através das palavras. Para ele se desligar do mundo lá fora e mergulhar nesse espaço de vivências, emoções e interatividades, o museu criou uma espécie de rito de passagem, uma preparação para o que está por vir.

Logo na chegada, ainda no térreo, o visitante encontra a Árvore da Lingua. As raízes são formadas por palavras e, nas folhas, são projetados os contornos de objetos. Ao entrar em um dos elevadores do saguão, fica conhecendo a Árvore de Palauras, uma grande escultura de 16 metros de altura, criada pelo designer Rafic Farah. Começando pelas raízes, é possível ler palavras com seis mil anos de idade, provenientes do indo-europeu, tataravô do nosso português. Subindo pelo tronco, vêem-se faixas de luz que produzem sombras nas folhas e objetos variados, dando a sensação de se enxergarem palavras em movimento, enquanto se é também envolvido pela música Lingua, Palavra, um mantra criado por Arnaldo Antunes, em colaboração com o poeta e antropólogo Antônio Risério, que brinca com as palavras língua e palavra em vários idiomas. $\mathrm{O}$ conjunto de sons e imagens proporciona uma experiência sensorial marcante durante a viagem do elevador.

No primeiro piso ficam a área de exposições temporárias, os terminais multimídia, os escritórios de gestão do conteúdo, as atividades educativas e a programação do museu. No segundo andar estão instalados a Grande Galeria, a Galeria das Influências, a Linha do Tempo e o Beco das Palauras.

A Grande Galeria é formada por um enorme painel feito de projeções de imagens e trabalho sonoro, compondo um mural em movimento. Ao atravessar esse espaço, o visitante vai se sentir em uma estação de trem. Como um túnel, um telão de 106 metros de comprimento corta o edifício de uma ponta a outra e na parede, que parece não ter fim, são projetados 11 filmes simultaneamente, todos dirigidos por Marcello Dantas, Victor Lopes e Carlos Nader. Cada filme, com duração de 6 minutos, ocupa 9 metros da parede e trata de um tema conhecido por nós, como cotidiano, dança, festas, carnaval, futebol, música, relações humanas, culinária, valores, saberes e um dedicado à matriz lusa. À medida que assiste, o visitante se identifica com as situações e descobre como o português falado hoje no Brasil influencia e é influenciado pelo dia-a-dia.

Entre uma exibição e outra, vemos uma imagem única. São quatro vinhetas que se revezam para esse grande final. Uma delas mostra um trem moderno chegando à estação, como se fosse possível ver através da parede o que acontece na gare da Estação da Luz, que fica exatamente atrás do telão. A Grande Galeria foi 
concebida a partir de uma ampla pesquisa de som e imagem realizada por Eloá Chouzal, Jorge Grinspum, Solange Santos, Mônica Médici, Marialice Generoso, Ana Lucia Pinho, Andréa Wanderley e Eduardo Magalhães, sob a orientação e coordenação de Helena Tassara. Os especialistas Antônio Risério, Manuela Carneiro da Cunha e Marilza Oliveira escreveram textos-base a partir dos quais Isa Grinspun Ferraz, Marcos Pompéia e Marcelo Macca escreveram os roteiros.

Depois de passar por filmes, quadros, fotos e vídeos, a história da língua portuguesa termina em um mapa animado dos falares do Brasil. Em uma tela interativa, é possível navegar pelo mapa do Brasil, selecionar um estado e ouvir o modo de falar dessa região.

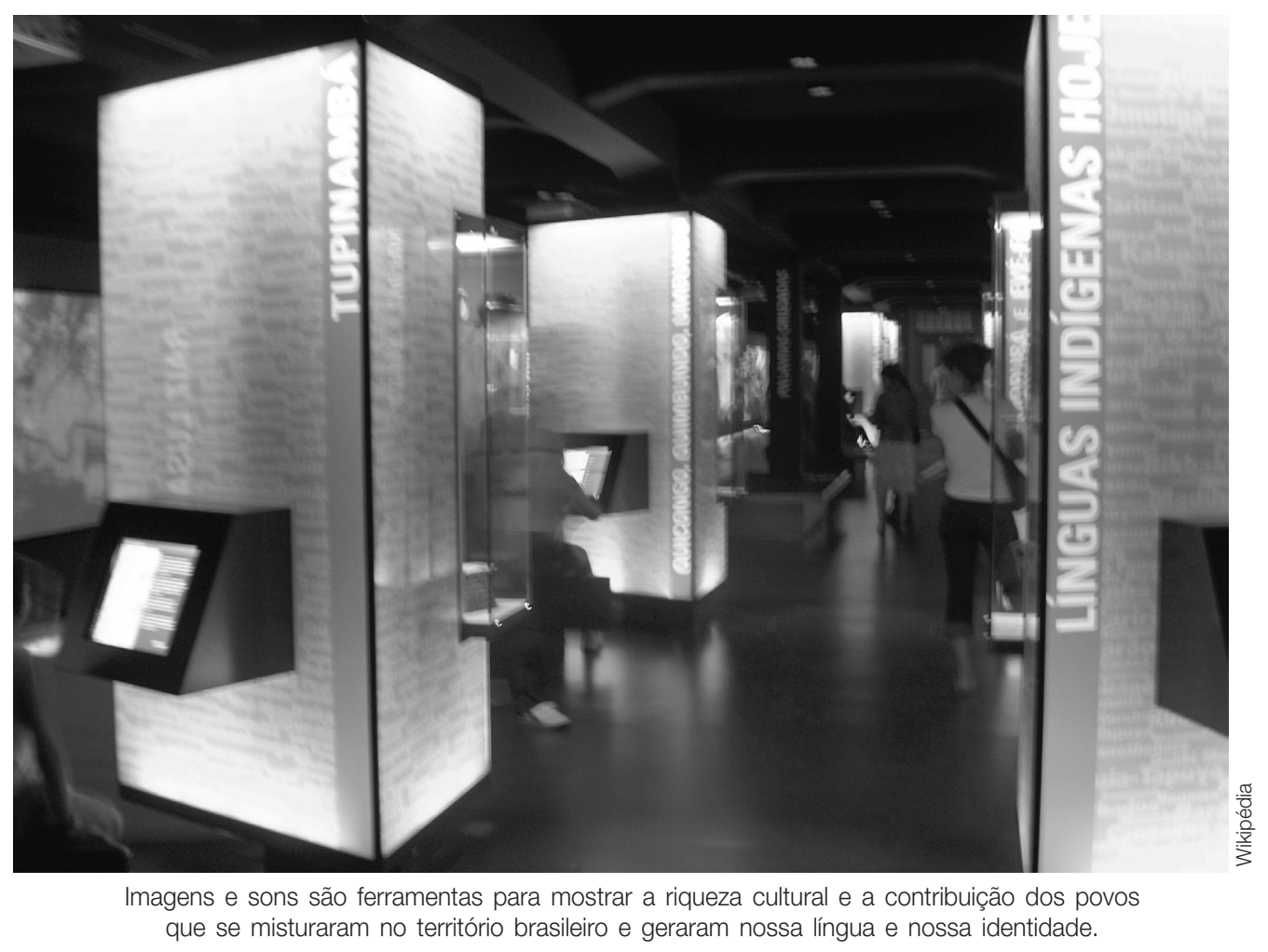

Na parte central do segundo pavimento do Museu da Língua Portuguesa, encontram-se oito totens multimídia, em formato triangular. Esse espaço recebeu o nome de Palavras Cruzadas e é dedicado às línguas que formaram e influenciaram o português falado no Brasil. São dois totens dedicados às línguas africanas, dois às línguas indígenas, um ao espanhol, um ao inglês e francês, um às línguas dos imigrantes e o último ao português no mundo. Cada uma das faces de cada totem possui um monitor interativo, onde se pode brincar com palavras da língua e ir aprendendo sobre sua origem. Através de imagens e sons é possível conhecer mais sobre a riqueza cultural e a contribuição desses povos que se misturaram no território brasileiro e geraram nossa língua e nossa identidade. O roteirista Marcelo Macca, sob a coordenação de Isa G. Ferraz, desenvolveu os conteúdos das telas multimídia a partir de textos dos especialistas Ataliba Teixeira de Castilho, Aryon Dall'Igna Rodrigues, Yeda Pessoa de 
Castro, Alberto da Costa e Silva, Ivo Castro, Carlos Alberto Ricardo, Marilza Oliveira, Ana Suely Cabral, Ieda Alves, Mirta Groppi, Oswaldo Truzzi e Mario Eduardo Viaro.

Na Linha do Tempo, telas interativas e vídeos ajudam a contar a história da língua portuguesa no Brasil. Lá está o resultado da pesquisa do professor Ataliba de Castilho sobre os seis mil anos da história da língua portuguesa. Em um grande painel, descobrem-se as origens das três línguas que formam o português falado no Brasil - o português de Portugal, a língua dos índios e dos africanos. Há uma seleção de 120 grandes obras da literatura brasileira, escolhidas por Alfredo Bosi, que fizeram história e representam a evolução de nossa língua e de nosso conhecimento.

No Beco das Palavras, um dos espaços mais lúdicos do Museu da Língua

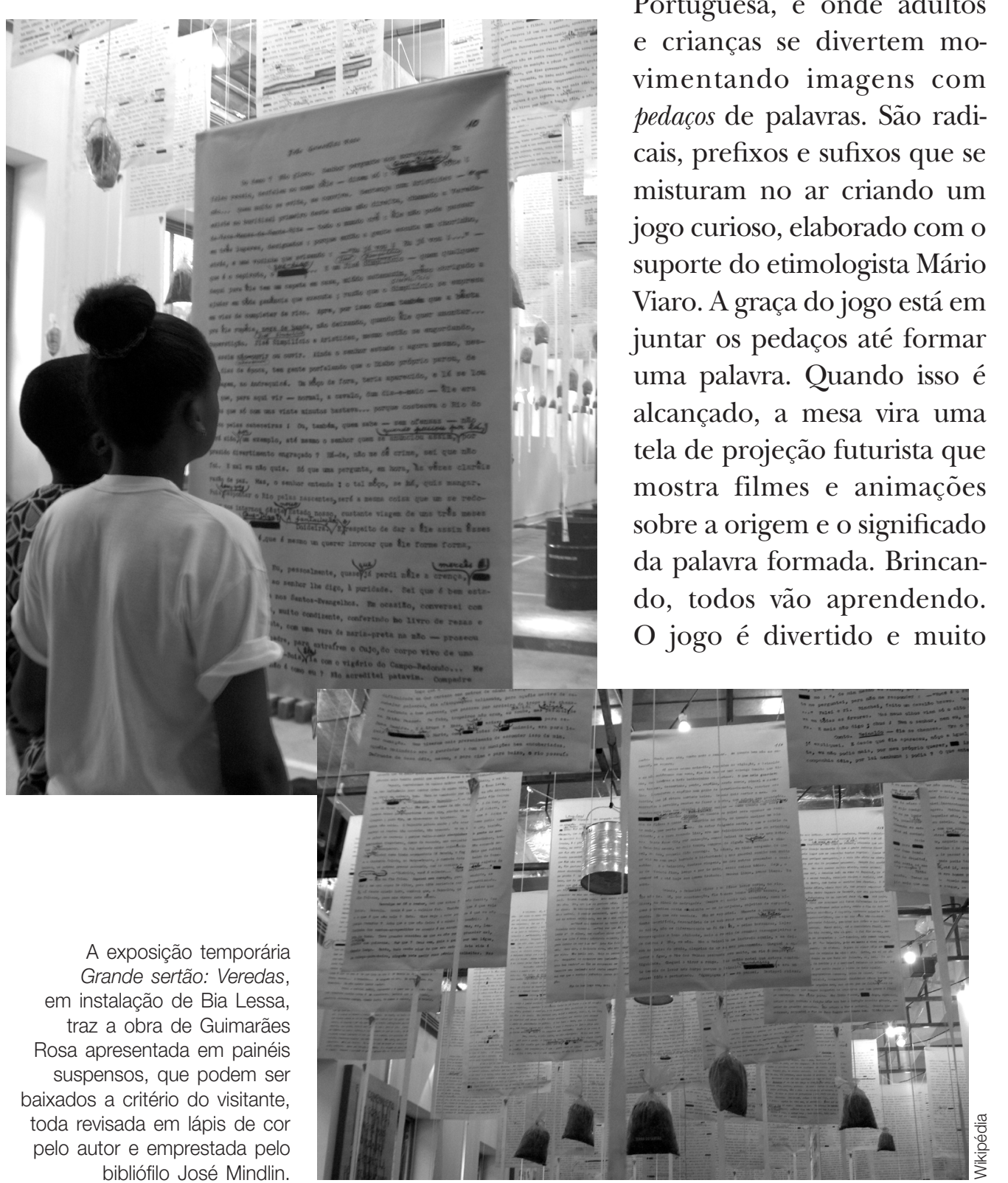


fácil, pois todas as palavras são de uso popular e não é preciso tocar na mesa para juntar os vários pedaços. A criação e direção é de Marcelo Tas, a direção artística de Marcello Dantas e animações e direção de arte de Liana Brazil; a tecnologia é de Russ Rive.

A concepção e a supervisão geral do Museu da Língua Portuguesa são de Hugo Barreto, a coordenação geral do projeto é de Silvia Finguerut, Jarbas Mantovanini e Lucia Basto.

No portal, pelo link Sobre o Projeto, os interessados podem conferir os créditos por completo e conhecer a caprichada lista de profissionais que trabalharam para organizar o museu.

\section{Serviço}

\section{Museu da Língua Portuguesa}

Praça da Luz, s/no, São Paulo.

Horário: terça-feira a domingo, das 10 às 18 horas.

Ingressos: $R$ \$ 4,00/inteira, $R$ \$ 2,00/meia (estudantes da rede pública). Gratuito para crianças até 10 anos e pessoas acima de 60 anos.

$<$ http://www.estacaodaluz.org.br>.

Resumo: Inaugurado em março de 2006, o Museu da Língua Portuguesa, na Estação da Luz, é a primeira instituição totalmente dedicada ao idioma original de um país. Com tecnologia de ponta, o museu apresenta toda a história da língua portuguesa, os vários idiomas que ajudaram a formá-la e a criação da língua na literatura brasileira. Além das áreas para exposições temporárias, terminais multimídias e escritórios de gestão de conteúdo, o visitante também tem acesso à Grande Galeria, à Galeria das Influências, à Linha do Tempo e ao Beco das Palavras. Atualmente, o português é a língua oficial de oito países, de quatro continentes: Portugal, Angola, Moçambique, São Tomé e Príncipe, Guiné-Bissau, Cabo Verde e Timor Leste, além do Brasil.

Palavras-chave: história, museu, língua portuguesa, Estação da Luz, interatividade.
Abstract: Inaugurated in March 2006, the Museum of Portuguese Language, at Luz Railway Station, is the first institution totally dedicated to the original language of a country. With top technology, it presents the History of Portuguese language, the several idioms that contributed to its formation and the creation of the language in the Brazilian literature. Besides the areas for temporary expositions, multimedia terminals and management offices, the visitor also has access to the Great Gallery, Gallery of Influences, Time Line and Alley of Words. Nowadays, Portuguese is the official language of eight countries in four continents: Portugal, Angola, Mozambique, Saint Thomas and Prince, Guinea Bissau, Cape Verde and East Timor, besides Brazil.

Keywords: history, museum, Portuguese language, Luz Railway Satation, interactivity. 